\title{
ESTIMASI PARAMETER MODEL ARELLANO DAN BOND PADA REGRESI DATA PANEL DINAMIS
}

\author{
Lailatul Urusyiyah \\ Mahasiswa Jurusan Matematika UIN Maulana Malik Ibrahim Malang \\ e-mail : lailatulurusyiyah@ymail.com
}

\begin{abstract}
ABSTRAK
Data panel merupakan gabungan dari cross section dan time series. Terdapat dua model data panel yaitu data panel statis dan dinamis. Karena melihat keunggulan model data panel dinamis yang sanggup mengatasi masalah endogenitas terkait penggunaan lag variabel dependen dimana pada model data panel statis penggunaan lag variabel dependen menyebabkan hasil estimasi menjadi bias dan tidak konsisten sehingga penulis meneliti tentang model regresi data panel dinamis.

Sebagai langkah awal untuk mengestimasi parameter yang tidak diketahui pada model regresi data panel dinamis yaitu dengan hanya memanfaatkan kondisi ortogonalitas yang ada di antara nilai-nilai lag dan error-nya maka model regresi data panel dinamis tersebut menjadi model Arellano dan Bond.

Untuk mengestimasi model Arellano dan Bond maka dilakukan beda pertama pada model tersebut, kemudian mencari matriks varians-kovarians dan mendefinisikan matriks instrumen dari model tersebut. Setelah itu, estimasi parameter model Arellano dan Bond menggunakan metode Generalized Least square (GLS). Berdasarkan pembahasan diperoleh rumus estimasi parameter model Arellano dan Bond adalah sebagai berikut:

$$
\hat{\delta}_{g l s}=\left(\Delta y_{-1} W\left(W\left(I_{N} \otimes G\right) W\right)^{-1} W \Delta y_{-1}\right)^{-1} \Delta y_{-1} W\left(W\left(I_{N} \otimes G\right) W\right)^{-1} \Delta y
$$
\end{abstract}

Kata Kunci: Regresi Data Panel Dinamis, Model Arellano dan Bond, Estimasi Parameter, Metode Generalized Least Square (GLS).

\section{ABSTRACT}

Panel Data is a combination of cross section and time series. There are two models of panel data namely static panel data and dynamic panel data. Because of seeing the advantage of dynamic panel data model is able to handle the problem of endogeneity related to the using of the dependent variable lag when static panel data used the dependent variable for causing the estimation result be biased and inconsistent. It makes the writer research the model of dynamic panel data regression.

For the first step to estimate unknown parameters of the regression dynamic panel data model by using orthogonality conditions that existed among Lag and an error values, so the regression dynamic panel data becomes Arellano and Bond model.

For estimating Arellano and Bond model, we differ that model for the first time, then we seek a matrix variance-covarriance and define matrix instruments of the model. Then, estimating of the Arellano and Bond model parameters using Generalized Least Square methods (GLS ). According to the mater we get the estimation formula parameters Arellano and Bond model as follow:

$$
\hat{\delta}_{g l s}=\left(\Delta y_{-1} W\left(W\left(I_{N} \otimes G\right) W\right)^{-1} W \Delta y_{-1}\right)^{-1} \Delta y_{-1} W\left(W\left(I_{N} \otimes G\right) W\right)^{-1} \Delta y
$$

Keywords: The dynamic panel data regression, Arellano and Bond Model, an Estimation of the parameters, a method of Generalized Least Square (GLS).

\section{PENDAHULUAN}

Pada penelitian ini penulis tertarik untuk mengkaji tentang data panel dinamis, dimana data panel merupakan gabungan antara data time series dan cross section. Terdapat beberapa model regresi data panel dinamis, yaitu model Arellano dan Bond, Arellano dan Bover, kondisi momen Ahn dan Schmidt, sistem GMM Blundel dan Bond, serta Keane dan Runkle. Dari beberapa model tersebut, bentuk yang paling sederhana adalah model Arellano dan Bond, sehingga penulis mengambil judul "Estimasi Parameter Model Arellano dan Bond pada Regresi Data Panel Dinamis".

\section{TEORI DASAR}

\section{A. Pendekatan Matriks untuk Model Regresi Linier}

Dengan menggeneralisasikan model regresi linier dua atau tiga variabel, maka model 
regresi populasi $k$-variabel yang melibatkan variabel tak bebas $y$ dan sebanyak $K-1$ variabel bebas $x_{2}, x_{3}, \ldots, x_{K}$ dapat ditulis sebagai

$$
y_{i}=\beta_{1}+\beta_{2} x_{2 i}+\beta_{3} x_{3 i}+\cdots+\beta_{K} x_{K i}+\varepsilon_{i}
$$

dimana $i=1,2, \ldots, N$ dan $\beta_{1}$ adalah intersep, $\beta_{2}$ sampai $\beta_{K}$ adalah koefisien kemiringan parsial, $\varepsilon$ unsur error stokastik, dan $i$ adalah observasi ke- $i$, $N$ merupakan besarnya populasi (Gujarati, 2004).

Untuk $i=1$ hingga $N$, persamaan di atas dapat ditulis sebagai:

$$
\begin{aligned}
& y_{1}=\beta_{1}+\beta_{2} x_{21}+\beta_{3} x_{31}+\cdots+\beta_{K} x_{K 1}+\varepsilon_{1} \\
& y_{2}=\beta_{1}+\beta_{2} x_{22}+\beta_{3} x_{32}+\cdots+\beta_{K} x_{K 2}+\varepsilon_{2} \\
& \vdots \\
& y_{N}=\beta_{1}+\beta_{2} x_{2 N}+\beta_{3} x_{3 N}+\cdots+\beta_{K} x_{K N}+\varepsilon_{N}
\end{aligned}
$$

persamaan tersebut dapat ditulis dengan cara lain yang lebih menjelaskan sebagai berikut:

$$
\left[\begin{array}{c}
y_{1} \\
y_{2} \\
\vdots \\
y_{N}
\end{array}\right]=\underbrace{\left[\begin{array}{ccccc}
1 & x_{21} & x_{31} & \cdots & x_{k 1} \\
1 & x_{22} & x_{32} & \cdots & x_{k 2} \\
\vdots & \vdots & \vdots & & \vdots \\
1 & x_{2 N} & x_{3 N} & \cdots & x_{k N}
\end{array}\right]}_{N \times 1}\left[\begin{array}{c}
\beta_{0} \\
\beta_{1} \\
\vdots \\
\beta_{k}
\end{array}\right]+\left[\begin{array}{c}
\varepsilon_{1} \\
\varepsilon_{2} \\
\vdots \\
\varepsilon_{N=1}
\end{array}\right]
$$

persamaan matriks tersebut dapat ditulis sebagai:

$$
y=X \beta+\varepsilon
$$

\section{B. Sifat-sifat Transpose}

Menurut Anton dan Rorres (2004), sifatsifat transpose antara lain:

(a) $\left((A)^{T}\right)^{T}=A$

(b) $(A+B)^{T}=A^{T}+B^{T} \operatorname{dan}(A-B)^{T}=A^{T}-B^{T}$

(c) $(k A)^{T}=k A^{T}$, dengan $k$ adalah skalar sebarang

(d) $(A B)^{T}=B^{T} A^{T}$

\section{Matriks Ortogonal}

Anton dan Rorres (2004) menyatakan bahwa matriks bujursangkar $A$ yang memiliki sifat

$$
A^{-1}=A^{T}
$$

disebut sebagai matriks ortogonal. Dari definisi ini diketahui bahwa matriks bujursangkar $A$ ortogonal jika dan hanya jika

$$
A A^{T}=A^{T} A=I
$$

\section{Metode Ordinary Least Square (OLS)}

Dalam penggunaan regresi, terdapat beberapa asumsi dasar yang dapat menghasilkan estimator linier tidak bias yang terbaik dari model regresi yang diperoleh dari metode kuadrat terkecil atau biasa dikenal dengan regresi OLS agar estimasi koefisien regresi itu bersifat BLUE (Best Linear Unbiased Estimator). Untuk tujuan ini maka perlu memilih parameter $\beta$ sehingga nilai fungsi,

$$
S=\varepsilon^{T} \varepsilon=(y-X \beta)^{T}(y-X \beta)
$$

sekecil mungkin (minimal).

Persamaan tersebut adalah skalar, sehingga komponen-komponennya juga skalar. Akibatnya, transpose skalar tidak mengubah nilai skalar tersebut. Sehingga $S$ dapat ditulis sebagai

$$
\begin{aligned}
S & =(y-X \beta)^{T}(y-X \beta) \\
& =\left(y^{T}-\beta^{T} X^{T}\right)(y-X \beta) \\
& =y^{T} y-y^{T} X \beta-\beta^{T} X^{T} y+\beta^{T} X^{T} X \beta \\
& =y^{T} y-\left(y^{T} X \beta\right)^{T}-\beta^{T} X^{T} y+\beta^{T} X^{T} X \beta \\
& =y^{T} y-\beta^{T} X^{T} y-\beta^{T} X^{T} y+\beta^{T} X^{T} X \beta \\
& =y^{T} y-2 \beta^{T} X^{T} y+\beta^{T} X^{T} X \beta
\end{aligned}
$$

Untuk meminimumkannya dapat di peroleh dengan melakukan turunan parsial pertama $S$ terhadap $\beta$,

$$
\begin{aligned}
\frac{d S}{d \beta} & =0-2 X^{T} y+X^{T} X \beta+\left(\beta^{T} X^{T} X\right)^{T} \\
& =-2 X^{T} y+X^{T} X \beta+X^{T} X \beta \\
& =-2 X^{T} y+2 X^{T} X \beta
\end{aligned}
$$

dan menyamakannya dengan nol diperoleh

$$
X^{T} X \beta=X^{T} y
$$

yang dinamakan sebagai persamaan normal, dan

$$
\hat{\beta}_{a s}=\left(X^{T} X\right)^{-1} X^{T} y
$$

\section{E. Metode Generalized Least Square (GLS)}

Menurut Greene (1997), penanggulangan kasus heteroskedastisitas dapat dilakukan dengan estimasi melalui pembobotan (weighted) yang dapat pula dikatakan sebagai kuadrat terkecil yang diberlakukan secara umum atau disebut Generalized Least Squares (GLS). Model persamaan linier umum adalah

$$
y=X \beta+\varepsilon
$$

dengan $\varepsilon \in N(0, \Phi)$, dimana 


$$
\Phi=\sigma^{2} \psi=\left[\begin{array}{cccc}
\sigma_{1}^{2} & 0 & \cdots & 0 \\
0 & \sigma_{2}^{2} & \cdots & 0 \\
\vdots & \vdots & & \vdots \\
0 & 0 & \cdots & \sigma_{n}^{2}
\end{array}\right]
$$

matriks simetri dan positive definite. Karena $\Phi$ matriks simetri dan positive definite maka ada matriks $C$ yang ortogonal $\left(C^{T} C=C C^{T}=I\right)$ sedemikian hingga $C^{T} \Phi C=D$ adalah matriks diagonal yang elemen-elemennya merupakan nilai-nilai eigen dari $\Phi$. Misalkan

$$
D=\left[\begin{array}{cccc}
\lambda_{1} & 0 & \cdots & 0 \\
0 & \lambda_{2} & \cdots & 0 \\
\vdots & \vdots & & \vdots \\
0 & 0 & \cdots & \lambda_{n}
\end{array}\right]
$$

dan tulis

$$
P=\left[\begin{array}{cccc}
\frac{1}{\sqrt{\lambda_{1}}} & 0 & \cdots & 0 \\
0 & \frac{1}{\sqrt{\lambda_{2}}} & \cdots & 0 \\
\vdots & \vdots & & \vdots \\
0 & 0 & \cdots & \frac{1}{\sqrt{\lambda_{n}}}
\end{array}\right]
$$

maka diperoleh $P^{T} D P=I$. Karena $C^{T} \Phi C=D$ maka $P^{T} C^{T} \Phi C P=P^{T} D P=I$. Misalkan $W=P C$ maka $\quad I=P^{T} C^{T} \Phi C P=W^{T} \Phi W \quad$ akibatnya diperoleh $\Phi=\left(W^{T}\right)^{-1} W^{-1}=\left(W^{T} W\right)^{-1} \quad$ atau $\Phi^{-1}=W^{T} W$.

Dari persamaan model statistik linier diperoleh transformasi model menjadi

$$
W y=W(X \beta+\varepsilon)=W X \beta+W \varepsilon
$$

atau

$$
y^{*}=X^{*} \beta+\varepsilon^{*}
$$

disebut sebagai Generalized Least Squares Estimator (GLSE), yaitu

$$
\begin{aligned}
\hat{\beta}_{g l s} & =\left(X^{* T} X^{*}\right)^{-1} X^{* T} y^{*} \\
& =\left[(W X)^{T}(W X)\right]^{-1}(W X)^{T}(W y) \\
& =\left(X^{T} W^{T} W X\right)^{-1} X^{T} W^{T} W y \\
& =\left(X^{T} \Phi^{-1} X\right)^{-1} X^{T} \Phi^{-1} y \\
& =\left(X^{T}\left(\sigma^{2} \psi\right)^{-1} X\right)^{-1} X^{T}\left(\sigma^{2} \psi\right)^{-1} y \\
& =\sigma^{2}\left(X^{T} \psi^{-1} X\right)^{-1} X^{T}\left(\frac{1}{\sigma^{2}}\right) \psi^{-1} y \\
& =\left(X^{T} \psi^{-1} X\right)^{-1} X^{T} \psi^{-1} y
\end{aligned}
$$

\section{F. Pengertian Data Panel}

Menurut Rosadi (2006) data panel adalah tipe data yang dikumpulkan menurut urutan waktu dalam suatu rentang waktu tertentu pada sejumlah individu atau kategori. Menurut Winarno (2007) data panel merupakan gabungan antara data silang (cross section) dengan data runtut waktu (time series). Menurut Setiawan dan Kusrini (2010) ada banyak sebutan untuk data panel ini, misalnya data terkelompok (pooled data), kombinasi berkala (kumpulan data berkala dan tampang lintang), data mikropanel (micropanel data), data bujur (longitudinal data atau studi sekian waktu pada sekelompok objek penelitian), analisis riwayat peristiwa (event history analysis) atau studi sepanjang waktu dari sekumpulan objek sampai mencapai keberhasilan atau kondisi tertentu.

Menurut Gujarati (2003) data panel dapat dibedakan menjadi dua, balanced panel dan unbalanced panel. Balanced panel terjadi jika panjangnya waktu untuk setiap unit cross section sama. Sedangkan unbalanced terjadi jika panjangnya waktu tidak sama untuk setiap unit cross section.

\section{G. Model Regresi Data Panel}

Menurut Firdaus (2004) analisis regresi adalah teknik analisis yang mencoba menjelaskan bentuk hubungan antara variabel yang mendukung sebab akibat. Regresi menggunakan data panel disebut model regresi data panel. Bentuk umum model regresi data panel adalah sebagai berikut:

$$
y_{i t}=x_{i t}^{T} \beta+\varepsilon_{i t}
$$

dimana:

$y=$ variabel terikat untuk unit individu ke- $i$ dan waktu ke- $t$

$x_{i t}^{\prime}=$ matriks dengan ordo $1 \times k$

$\beta=$ parameter yang tidak diketahui dengan matriks $k \times 1$

$\varepsilon_{i t}=$ error untuk unit individu ke- $i$ dan waktu ke- $t$

$i=1,2, \ldots, N$ untuk unit individu

$t=1,2, \ldots, T$ untuk waktu

\section{H. Model Regresi Data Panel dinamis}

Analisis data panel dapat digunakan pada model yang bersifat dinamis karena data panel cocok untuk analisis dynamic of adjusment. 
Sejalan dengan adanya model cross section atau time series, hubungan dinamis yang dicirikan oleh data panel dengan memasukkan lag dari peubah atau variabel dependen sebagai regresor dalam regresi. Akibatnya muncul masalah endogenitas, sehingga bila model diestimasi dengan pendekatan fixed-effect maupun random-effect akan menghasilkan penduga yang bias dan tidak konsisten. Untuk itu maka muncul pendekatan GMM (Generalized Method of Moments). Sebagai ilustrasi, dapat diketahui dengan model data panel dinamis yang telah dikemukakan oleh Baltagi (2005) sebagai berikut:

$$
y_{i t}=\delta y_{i, t-1}+X_{i t}^{T} \beta+u_{i t}
$$

untuk $i=1,2,3, \ldots, n$ dan $t=1,2,3, \ldots, T$.

dimana $\delta$ menyatakan besaran skalar, $x_{i t}^{\prime}$ menyatakan matriks berukuran $1 \times k$ dan $\beta$ berukuran $k \times 1$. Dalam hal ini $\varepsilon_{i t}$ diasumsikan mengikuti model one way error component sebagai berikut:

$$
u_{i t}=\varpi_{i}+\pi_{i t}
$$

dimana $\varpi_{i} \sim \operatorname{IID}\left(0, \sigma_{\varpi}^{2}\right)$ menyatakan pengaruh individu dan $\pi_{i t} \sim \operatorname{IID}\left(0, \sigma_{\pi}^{2}\right)$ menyatakan error yang saling bebas satu sama lain.

\section{Kronecker Product}

Menurut Graham (1981), misalkan matriks $A=\left[a_{i j}\right]$ dengan ordo $m \times n$ dan makriks $B=\left[b_{i j}\right]$ dengan ordo $r \times s$. Kronecker product dari kedua matriks tersebut, disimbolkan dengan $A \otimes B$ adalah matriks partisi

$$
A \otimes B=\left[\begin{array}{cccc}
a_{11} B & a_{12} B & \cdots & a_{1 n} B \\
a_{21} B & a_{22} B & \cdots & a_{2 n} B \\
\vdots & \vdots & \ddots & \vdots \\
a_{m 1} B & a_{m 2} B & \cdots & a_{n n} B
\end{array}\right]
$$

$A \otimes B$ dipandang matriks berordo $m r \times n s$.

\section{PEMBAHASAN}

\section{A. Model Regresi Data Panel Dinamis}

Bentuk umum model data panel dinamis adalah sebagai berikut:

$$
y_{i t}=\delta y_{i, t-1}+x_{i t}^{T} \beta+u_{i t}
$$

dengan $u_{i t}$ diasumsikan mengikuti one way error component sebagai berikut:

$$
u_{i t}=\varpi_{i}+\pi_{i t}
$$

Dengan menggabungkan persamaan (1) dan (2), maka diperoleh:

$$
y_{i t}=\delta y_{i, t-1}+x_{i t}^{T} \beta+\varpi_{i}+\pi_{i t}
$$

Dimana:

$$
\begin{aligned}
y_{i t}= & \begin{array}{l}
\text { variabel terikat untuk unit } \\
\text { individu ke- } i \text { dan waktu ke- } t \\
\text { variabel bebas untuk unit individu }
\end{array} \\
y_{i, t-1}= & \begin{array}{l}
\text { ke- } i \text { dan waktu ke- } t \\
\text { koefisien lag variabeldependen } \\
\text { matriks berukuran }(1 \times K) \text { yang }
\end{array} \\
x_{i t}^{T}= & \text { berisikan variabel bebas untuk } \\
& \text { unit individu ke- } i \text { dan waktu ke- } t \\
& \text { matriks berukuran }(1 \times K) \text { yang } \\
\beta= & \text { berisikan parameter variabel } \\
& \text { bebas } \\
u_{i t}= & \text { error untuk unit individu ke- } i \text { dan } \\
& \text { waktu ke- } t \\
\varpi_{i}= & \text { error untuk cross-section } \\
\pi_{i t}= & \text { error atau gangguan yang saling } \\
i \quad= & \text { bebas satu sama lain } \\
t \quad= & 1,2, \ldots, N
\end{aligned}
$$

Karena $x_{i t}^{T}$ adalah matriks yang berukuran $(1 \times K)$ dan $\beta$ adalah matriks yang berukuran $(K \times 1)$, maka persamaan (3) menjadi:

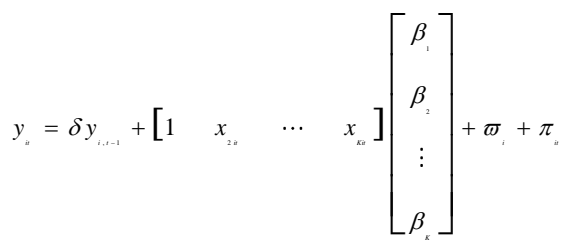

$$
\begin{aligned}
& =\delta y_{1,+1}+\beta_{1}+x_{20} \beta_{2}+\cdots+x_{\mathrm{ks}} \beta_{\mathrm{x}}+\varpi_{i}+\pi \\
& =\delta y_{1,-1}+\beta_{+}+\sum^{k} x_{\omega} \beta_{+}+\varpi+\pi
\end{aligned}
$$

untuk $t=2$ hingga $t=T$ persamaan tersebut menjadi:

$$
\begin{aligned}
& y_{12}=\delta y_{11}+\beta_{1}+\sum_{w_{22}}^{x} \beta_{1}+\varpi_{1}+\pi \\
& y_{i, 2}=\delta y_{i 2}+\beta_{i}+\sum^{k} x_{k 3} \beta_{c}+\sigma_{t}+\pi
\end{aligned}
$$

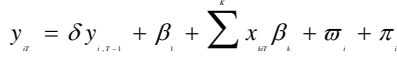

atau dapat ditulis dalam bentuk persamaan matriks sebagai berikut:

$$
\begin{aligned}
\underbrace{\left[\begin{array}{c}
y_{i 2} \\
\vdots \\
y_{i T}
\end{array}\right]}_{N(T-1) \times 1}= & \delta \underbrace{\left[\begin{array}{c}
y_{i 1} \\
\vdots \\
y_{i(T-1)}
\end{array}\right]}_{N(T-1) \times 1}+\underbrace{\left[\begin{array}{cccc}
1 & x_{2 i 2} & \cdots & x_{K i 2} \\
\vdots & \vdots & \ddots & \vdots \\
1 & x_{2 i T} & \cdots & x_{K i T}
\end{array}\right]}_{N(T-1) \times K} \underbrace{\left[\begin{array}{c}
\beta_{1} \\
\vdots \\
\beta_{K}
\end{array}\right]}_{K \times 1} \\
& +\underbrace{\left[\begin{array}{c}
\varpi_{i} \\
\vdots \\
\varpi_{i}
\end{array}\right]}_{N(T-1) \times 1}+\underbrace{\left[\begin{array}{c}
\pi_{i 2} \\
\vdots \\
\pi_{i T}
\end{array}\right]}_{N(T-1) \times 1}
\end{aligned}
$$


Dalam penelitian kali ini, peneliti hanya akan mengestimasi parameter $\delta$ yang merupakan langkah awal (pre-estimation) model regresi data panel dinamis. Karena dengan diketahuinya parameter $\delta$, maka untuk langkah selanjutnya yaitu mengestimasi parameter $\beta$ dapat dilakukan dengan mudah menggunakan estimasi Ordinary Least Square (OLS) atau Maximum Likelihood (ML).

\section{B. Model Arellano dan Bond pada Data Panel Dinamis}

Arellano dan Bond berpendapat bahwa tambahan instrumen dapat diperoleh dalam model data panel dinamis jika memanfaatkan kondisi ortogonalitas yang ada di antara nilai-nilai lag dari $y_{i t}$ dan gangguan $v_{i t}$. Sehingga tanpa regressor, persamaan (1) dapat ditulis sebagai berikut:

$$
y_{i t}=\delta y_{i, t-1}+\varepsilon_{i t}
$$

untuk $i=1,2, \ldots, N$; dan $t=2,3, \ldots, T$

$\varepsilon_{i t}$ pada persamaan (4) diasumsikan mengikuti model one way error component sebagai berikut:

$$
\varepsilon_{i t}=\mu_{i}+v_{i t}
$$

dimana $\mu_{i} \sim \operatorname{IID}\left(0, \sigma_{\mu}^{2}\right)$ menyatakan pengaruh individu dan $v_{i t} \sim I I D\left(0, \sigma_{\mu}^{2}\right)$ menyatakan gangguan yang saling bebas satu sama lain. Dengan menstubtitusikan persamaan (5) pada persamaan (4), maka diperoleh

$$
y_{i t}=\delta y_{i, t-1}+\mu_{i}+v_{i t}
$$

untuk $i=1,2,3, \ldots, N$

$$
t=1,2,3, \ldots, T
$$

untuk $i=1,2, \ldots, N$ dan $t=2,3, \ldots, T$ adalah sebagai berikut:

$$
\begin{aligned}
& y_{12}=\delta y_{11}+\mu_{11}+v_{12} \\
& y_{22}=\delta y_{21}+\mu_{2}+v_{22} \\
& \vdots \\
& y_{N 2}=\delta y_{N 1}+\mu_{N}+v_{N 2} \\
& y_{13}=\delta y_{12}+\mu_{1}+v_{13} \\
& y_{23}=\delta y_{22}+\mu_{2}+v_{23} \\
& \vdots \\
& y_{N 3}=\delta y_{N 2}+\mu_{N}+v_{N 3} \\
& \vdots \\
& y_{1 T}=\delta y_{1, T-1}+\mu_{1}+v_{1 T} \\
& y_{2 T}=\delta y_{2, T-1}+\mu_{2}+v_{2 T} \\
& \vdots \\
& y_{N T}=\delta y_{N, T-1}+\mu_{N}+v_{N T}
\end{aligned}
$$

atau dapat ditulis dalam bentuk persamaan matriks sebagai berikut:

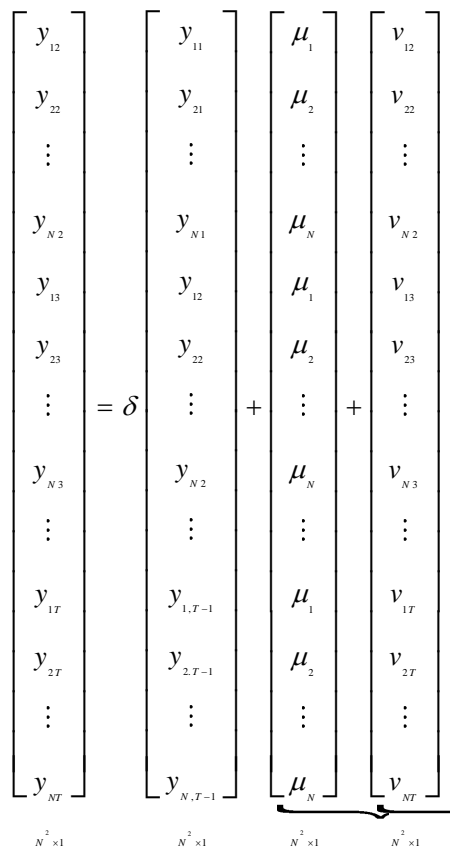

\section{Estimasi Parameter Model Arellano dan Bond}

Untuk mendapatkan estimasi yang konsisten dari $\delta$ dimana $N \rightarrow \infty$ dengan $T$ tertentu, maka dilakukan beda pertama pada persamaan (6) yaitu

$$
\begin{aligned}
& y_{t i}-y_{t,-1-1}=\delta\left(y_{t, t-1}-y_{t, t-2}\right)+\left(\left(\mu_{i}+v_{i t}\right)-\left(\mu_{i}+v_{t, t-1}\right)\right) \\
& =\delta\left(y_{i t-1}-y_{i t-2}\right)+\left(\mu+v_{i}-\mu-v_{i t-1}\right) \\
& =\delta\left(y_{i=1}-y_{t-2-2}\right)+\left(v_{i-1}-v_{i-1}\right)
\end{aligned}
$$

misalkan $y_{i t}-y_{i, t-1}=\Delta y$ dan $v_{i t}-v_{i, t-1}=\Delta v$, maka persamaan tersebut menjadi:

$$
\Delta y=\delta \Delta y_{-1}+\Delta v
$$

dimana $\left(v_{i t}-v_{i, t-1}\right)$ adalah MA (1) dengan unit root.

- Untuk $t=3$ maka

$$
y_{i 3}-y_{i 2}=\delta\left(y_{i 2}-y_{i 1}\right)+\left(v_{i 3}-v_{i 2}\right)
$$

$y_{i 1}$ pada persamaan tersebut merupakan variabel instrumental yang valid, karena $y_{i 1}$ berkorelasi dengan $\left(y_{i 2}-y_{i 1}\right)$ dan tidak berkorelasi dengan error-nya yaitu $\left(v_{i 3}-v_{i 2}\right)$ selama $v_{i t}$ tidak berkorelasi serial.

- Untuk $t=4$ maka

$$
y_{i 4}-y_{i 3}=\delta\left(y_{i 3}-y_{i 2}\right)+\left(v_{i 4}-v_{i 3}\right)
$$

dengan variabel instrumental yang valid adalah $y_{i 2}$.

- Untuk $t=5$, maka 


$$
y_{i 5}-y_{i 4}=\delta\left(y_{i 4}-y_{i 3}\right)+\left(v_{i 5}-v_{i 4}\right)
$$

dengan variabel instrumental yang valid adalah $y_{i 3}$. Begitu seterusnya hingga $t=T$ dengan variabel instrumental yang valid adalah $y_{i, T-2}$, jadi himpunan variabel instrumental yang valid adalah $\left\{y_{i 1}, y_{i 2}, y_{i 3}, \ldots, y_{i, T-2}\right\}$.

Jika ditulis dalam bentuk matriks untuk $t=3$ hingga $t=T$, maka diperoleh hasil sebagai berikut:

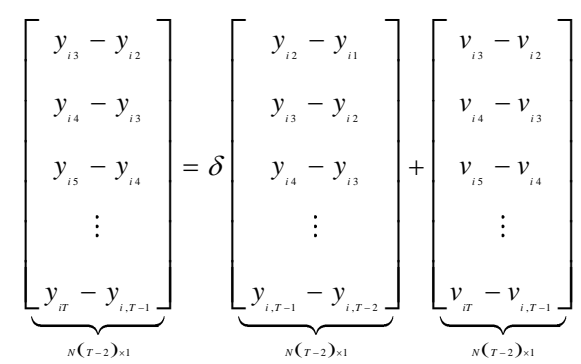

sehingga, matriks varians-kovarians dari error ( $v_{i t}$ ) pada persamaan (4) dengan $t=3$ hingga $t=T$ dapat ditulis :

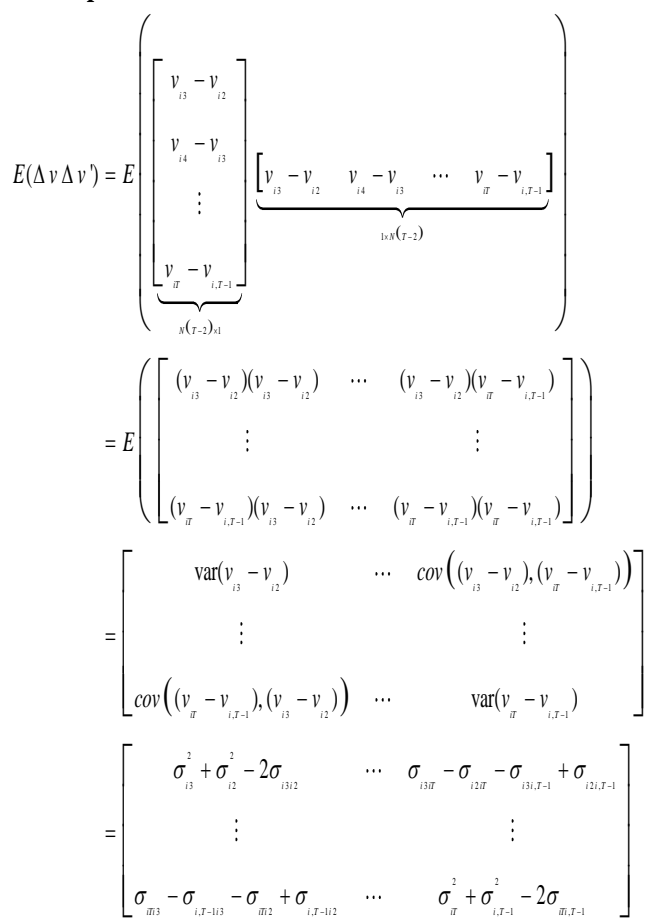

Karena $v_{i t} \sim \operatorname{IID}\left(0, \sigma_{v}^{2}\right)$ maka $\sigma_{i t}^{2}=\sigma_{v}^{2}, \forall t$ dan $\forall i$ begitu juga kovariansnya adalah 0 , sehingga matriks varians-kovarians di atas dapat ditulis sebagai

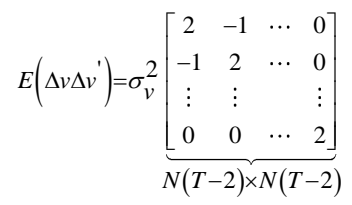

Agar terdapat identitas pada persamaan tersebut, maka misalkan $G=\left[\begin{array}{cccc}2 & -1 & \cdots & 0 \\ -1 & 2 & \cdots & 0 \\ \vdots & \vdots & & \vdots \\ 0 & 0 & \cdots & 2\end{array}\right]$ yang berordo $(T-2) \times(T-2)$, sehingga menurut definisi Kronecker product persamaan tersebut dapat ditulis sebagai berikut:

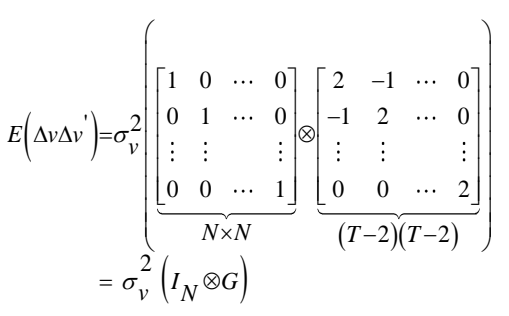

Didefinisikan $W_{i}$ adalah matriks yang elemen diagonal utamanya merupakan matriks dari variabel instrumental yang valid dengan ordo $(T-2) \times\left(\frac{(T-2)(T-1)}{2}\right)$ yaitu

$$
W_{i t}=\left[\begin{array}{cccc}
{\left[y_{t 1}\right]} & 0 & \cdots & 0 \\
0 & {\left[y_{i 1}, y_{t 2}\right]} & \cdots & 0 \\
\vdots & \vdots & & \vdots \\
0 & 0 & \cdots & {\left[y_{i 1}, \ldots, y_{t, T-2}\right]}
\end{array}\right]
$$

maka matriks instrumennya adalah

$$
W=\left[\begin{array}{llll}
W_{1}^{T} & W_{2}^{T} & \cdots & w_{N}^{r}
\end{array}\right]^{r}
$$

dengan ordo $N(T-2) \times\left(\frac{(T-2)(T-1)}{2}\right) \quad$ dan persamaan momennya adalah $E\left(W_{i}^{T} \Delta v_{i}\right)=0$. Dengan perkalian kiri $W^{T}$, didapatkan

$$
W^{T} \Delta y=W^{T}\left(\Delta y_{-1}\right) \delta+W^{T} \Delta v
$$

Persamaan merupakan persamaan semi linier, sehingga $\delta$ dapat diestimasi secara GLS sebagai berikut, misalkan:

$$
\begin{aligned}
\Delta y^{*} & =W^{T} \Delta y \\
\Delta y_{-1}{ }^{*} & =W^{T} \Delta y_{-1} \\
\Delta v^{*} & =W^{T} \Delta v
\end{aligned}
$$

maka persamaan (7) menjadi

$$
\Delta y^{*}=\Delta y_{-1}{ }^{*} \delta+\Delta v^{*}
$$

dimana,

$$
\begin{aligned}
& E\left(\Delta v^{*}\right)=E\left(W^{T} \Delta v\right)=W^{T} E(\Delta v)=0 \\
& \text { dan } \\
& E\left(\Delta v^{*} \Delta v^{* T}\right)=E\left(W^{T} \Delta v\left(W^{T} \Delta v\right)^{T}\right)=E\left(W^{T} \Delta v \Delta v^{T} W\right) \\
& =W^{T} E\left(\Delta v \Delta v^{T}\right) W=W^{T}\left(\sigma^{2}\left(I_{N} \otimes G\right)\right) W \\
& \text { dengan ordo }\left(\frac{(T-2)(T-1)}{2}\right) \times\left(\frac{(T-2)(T-1)}{2}\right) \text {. }
\end{aligned}
$$


Error pada persamaan (8) diasumsikan Independent Identically Distribution (IID) yaitu $\Delta v^{*} \sim I I D(0, \Phi)$, sehingga:

$\Phi=\sigma_{v}^{2} \psi=W^{T} \sigma_{v}^{2}\left(I_{N} \otimes G\right) W=\sigma_{v}^{2}\left(W^{T}\left(I_{N} \otimes G\right) W\right)$ matriks

simetri dan positive definite. Karena $\Phi$ matriks simetri dan positive definite maka ada sebarang matriks $C$ yang orthogonal $\left(C C^{T}=C^{T} C=I\right)$

sedemikian hingga $C^{T} \Phi C=D$ adalah matriks yang elemen diagonal utamanya merupakan nilainilai eigen dari $\Phi$, maka

$$
D=\left[\begin{array}{cccc}
\lambda_{1} & 0 & \cdots & 0 \\
0 & \lambda_{2} & \cdots & 0 \\
\vdots & \vdots & & \vdots \\
0 & 0 & \cdots & \lambda_{n}
\end{array}\right]
$$

dan misalkan $P$ adalah matriks yang elemen diagonal utamanya adalah $\frac{1}{\sqrt{\lambda_{i}}}$. Sehingga dapat ditulis

$$
P=\left[\begin{array}{cccc}
\frac{1}{\sqrt{\lambda_{1}}} & 0 & \cdots & 0 \\
0 & \frac{1}{\sqrt{\lambda_{2}}} & \cdots & 0 \\
\vdots & \vdots & & \vdots \\
0 & 0 & \cdots & \frac{1}{\sqrt{\lambda_{n}}}
\end{array}\right]
$$

maka diperoleh $P^{T} D P=I$. Karena $C^{T} \Phi C=D$, maka $P^{T} C^{T} \Phi C P=P^{T} D P=I$. Misalkan $W=P C$ maka $I=P^{T} C^{T} \Phi C P=W^{T} \Phi W$, akibatnya diperoleh

$$
\begin{aligned}
\Phi & =\left(W^{T}\right)^{-1} W^{-1}=\left(W^{T} W\right)^{-1} \\
\Phi^{-1} & =W^{T} W
\end{aligned}
$$

sehingga bentuk estimator model Arellano dan Bond adalah sebagai berikut:

$$
\begin{aligned}
& \hat{\delta}_{g k}=\left(\Delta y_{-1}{ }^{-T} \Delta y_{-1}{ }^{\top}\right)^{-1} \Delta y_{-1}{ }^{-T} \Delta y \\
& =\left(\left(W^{\tau} \Delta y_{-1}\right)^{\tau}\left(W^{T} \Delta y_{-1}\right)\right)^{-1}\left(W^{\tau} \Delta y_{-1}\right)^{T}\left(W^{T} \Delta y\right) \\
& =\left(\Delta y_{-1}{ }^{T} W W^{T} \Delta y_{-1}\right)^{-1} \Delta y_{-1}{ }^{T} W W^{T} \Delta y \\
& =\left(\Delta y_{-1}{ }^{T} W W^{T} W W^{T} \Delta y_{-1}\right)^{-1} \Delta y_{-1}{ }^{T} W W^{T} W W^{T} \Delta y \\
& =\left(\Delta y_{-1}{ }^{T} \mathrm{~W} \Phi^{-1} W^{T} \Delta y_{-1}\right)^{-1} \Delta y_{-1}{ }^{T} \mathrm{~W} \Phi^{-1} W^{T} \Delta y \\
& =\left(\Delta y_{-1}{ }^{T} W\left(\sigma_{v}{ }^{2} \psi\right)^{-1} W^{T} \Delta y_{-1}\right)^{-1} \Delta y_{-1}{ }^{T} W\left(\sigma_{v}{ }^{2} \psi\right)^{-1} W^{T} \Delta y \\
& =\left(\Delta y_{-1}{ }^{T} W\left(W^{T}\left(I_{N} \otimes G\right) W\right)^{-1}\right) W^{T} \Delta y_{-1} \Delta y_{-1}{ }^{T} W \\
& \left(W^{T}\left(I_{N} \otimes G\right) W\right)^{-1} \Delta y
\end{aligned}
$$

yang dikatakan sebagai bentuk akhir estimator parameter $\delta$ untuk model Arellano dan Bond.

\section{PENUTUP}

Berdasarkan pembahasan diperoleh kesimpulan bahwa model Arellano dan Bond dapat diperoleh dengan hanya memanfaatkan kondisi ortogonalitas yang ada di antara nilai-nilai lag dan error pada regresi data panel dinamis, sehingga diperoleh:

$$
y_{i t}=\delta y_{i, t-1}+\varepsilon_{i t}
$$

$\varepsilon_{i t}$ pada persamaan tersebut diasumsikan mengikuti model one way error component sebagai $\quad \varepsilon_{i t}=\mu_{i}+v_{i t}$, dimana $\mu_{i} \sim \operatorname{IID}\left(0, \sigma_{\mu}^{2}\right)$ menyatakan pengaruh individu dan $v_{i t} \sim I I D\left(0, \sigma_{v}^{2}\right)$ menyatakan gangguan yang saling bebas satu sama lain. Untuk mendapatkan estimasi yang konsisten dari $\delta$ dimana $N \rightarrow \infty$ dengan $T$ tertentu, maka dilakukan beda pertama pada model tersebut, kemudian mencari matriks varians-kovarians dari error dan mendefinisikan matriks instrumen dari model tersebut. Setelah itu, estimasi parameter model Arellano dan Bond menggunakan metode Generalized Least square (GLS). Berdasarkan pembahasan diperoleh rumus estimasi parameter model Arellano dan Bond dengan metode GLS adalah sebagai berikut:

$\hat{\delta}_{g l s}$

$=\left(\Delta y_{-1} W\left(W\left(I_{N} \otimes G\right) W\right)^{-1}\right) W \Delta y_{-1} W\left(W\left(I_{N} \otimes G\right)\right)$

Pada penelitian selanjutnya dapat meneruskan untuk mencari parameter regresi data panel dinamis pada variabel eksogennya dan dapat mengaplikasikan model tersebut pada permasalahan-permasalahan yang terkait dengan ekonometri.

\section{DAFTAR PUSTAKA}

[1] Anton, H. dan Rorres, C.. 2004. Aljabar Linier Elementer Versi Aplikasi; alih bahasa, Refina Indriasari, Irzam Harmein; editor, Amalia Safitri Edisi Delapan Jilid 1. Jakarta: Erlangga.

[2] Aziz, A.. 2010. Ekonometrika Teori dan Praktek Eksperimen dengan MATLAB. Malang: UIN-Maliki Press.

[3] Baltagi, B.H.. 2005. Econometric Analysis of Panel Data, Third Edition. England: John Wiley \& Son, Ltd.

[4] Dudewicz, E.J. dan Mishra, S.H.. 1995. Statistika Matematika Modern; terjemahan RK Sembiring. Bandung: ITB.

[5] Firdaus, M.. 2004. Ekonometrika Suatu Pendekatan Aplikatif. Jakarta: Bumi Aksara. 
[6] Graham, A.. 1981. Kronecker Products and Matrix Calculus: with Application. England: IEB.

[7] Greene, W.H.. 1997. Econometric Analysis. New York: Prentice Hall International, Inc.

[8] Gujarati, D.N.. 2003. Basic Econometrics. New York: McGraw-Hill.

[9] Gujarati, D.N. 2004. Basic Econometrics, Fourth edition. New York: McGraw-Hill.
[10] Rosadi, D. 2006. Diktat Kuliah Pengantar Analisis Runtun Waktu. Yogyakarta: UGM.

[11] Setiawan \& Kusrini,D.E. 2010. Ekonometrika Yogyakarta: C.V ANDI OFFSET.

[12] Winarno,W.W..2007. Analisis Ekonometrika dan Statistika Eviews. Yogyakarta: UPP STIM YKPN. 